\title{
Pensamentos no gerúndio, Como DOCENTE, ARTISTA, CURADORA
}

\author{
Maria do Carmo Nino
}

\begin{abstract}
RESUMo
Apresento um relato da minha experiência enquanto produtora de trabalho artístico, curadora de exposições, analista cultural e artística. Neste artigo será dada particular relevância a duas experiências artísticas - Projeto MAMÃE, com reflexão em torno da obra Olho Mágico, e a Exposição ContidoNãoContido. A obra Olho Mágico surge como comentário autorreferencial, paródico. A transformação de uma parede cega em uma espécie de janela, como que intermedeia os possíveis diálogos entre o que se percebe como espaço interior e exterior. Na exposição ContidoNãoContido procuramos suscitar no visitante a necessidade de desconstruir criticamente a "reverência de tom forçado" frequentamente associada ao museu.
\end{abstract}

\section{Palavras-chave}

Arte; museu; desconstrução; diálogo

\begin{abstract}
This article presents my experience as a producer of artistic works, exhibition curator and cultural and artistic analyst. I will place special relevance on two artistic experiences - the MAMÃE Project, that revolves around the work, Olho Mágico [Magic Eye], and the Exhibition ContidoNãoContido. The work Olho Mágico appears as a self-referential comment, a parody. A blind wall is transformed into a kind of window, as if mediating the possible dialogues between what is perceived as interior and exterior space. In the exhibition ContidoNãoContido we aimed to encourage visitors to feel the need to critically deconstruct the sense of "obliged reverence" often associated to museums.
\end{abstract}

\section{PALAVRAS-ChAVE}

Art; museum; deconstruction; dialogue

Só o imaginário pode desenvolver o germe.

(Deleuze, 1985, p. 120)

\section{UM POUCO DA MINHA HISTÓRIA}

Graduei-me no bacharelado em arquitetura em 1980, pois na época era o curso existente em minha cidade que mais se aproximava de uma ideia de criação contendo características de visualidade em formas, cores, volume, espaço. Depois tive a oportunidade 
de fazer meus estudos de pós-graduação em Paris 1- Sorbonne, na área de Artes Visuais (processos artísticos). Minha produção plástica começa efetivamente a partir desta estadia parisiense (ocorrida entre 1988 e 1995), anos que foram extremamente ricos e importantes para que me descobrisse como indivíduo e como artista.

No retorno ao Brasil, me tornei professora de Artes Visuais na Universidade Federal de Pernambuco (UFPE), onde me encontro até hoje. Na função de transmissora de conhecimento específico sobre questões de cunho artístico, o contato também com outros professores, artistas e gestores tem sido constante.

Consequentemente, este foi um papel que se viu consideravelmente ampliado para uma participação mais efetiva em vários setores ligados às artes plásticas: enquanto produtora do trabalho artístico, curadora de exposições, analista cultural e artística da produção estética.

Nas minhas atividades desde então encontram-se perfeitamente amalgamadas a experiência da curadoria de exposições e da escrita de textos sobre artistas, assim como do ensino na graduação em Artes Visuais e também e na pós-graduação do programa de Literatura (no seu diálogo intersemiótico com as artes visuais). A efetivação da minha própria prática artística se vê então constantemente influenciada por estas atividades entre a produção verbal e não-verbal, de modo que não consigo estabelecer hierarquias entre as mesmas para a constituição da minha trajetória no geral.

Em meu trabalho pessoal, embora de maneira não exclusiva, continuo fiel à imagem, uma paixão que permanece viva desde o início, e que transita entre as práticas da pintura, do desenho e da fotografia, com uma ênfase particular por esta última como catalisadora inicial do processo, o que me aproximou de experiências com a imagem digital. Identifico-me com séries, sequencialidades, narrativas, modulações, pela dimensão processual que se estabelece com a ideia de devir, de intrínseco inacabamento, um conceito que me é muito caro e com o qual tenho trabalhado sempre.

Como gosto de experimentações, com o tempo e experiência com a interface digital, comecei a introduzir também na fotografia, o desenho e a própria pintura, a partir da manipulação diretamente no computador ou mesmo sobre a própria imagem impressa. Enfim todas elas são palimpsestos, hibridizações nas quais creio se inserir a própria ideia de transformação e de temporalidades. Me estimula bastante pensar o quanto podemos utilizar as ferramentas digitais para trabalhar as linguagens básicas do desenho e da pintura (ponto, linha, cor, mancha), em suas diversas nuances, tirando partido exatamente do leque vastíssimo de opções oferecidas por estes meios (duplicar, redimensionar, inverter, mesclar, distorcer, graduar a intensidade, etc.), valores que não podem ser obtidos por outro modo com a mesma precisão ou controle. Eis alguns exemplos: 


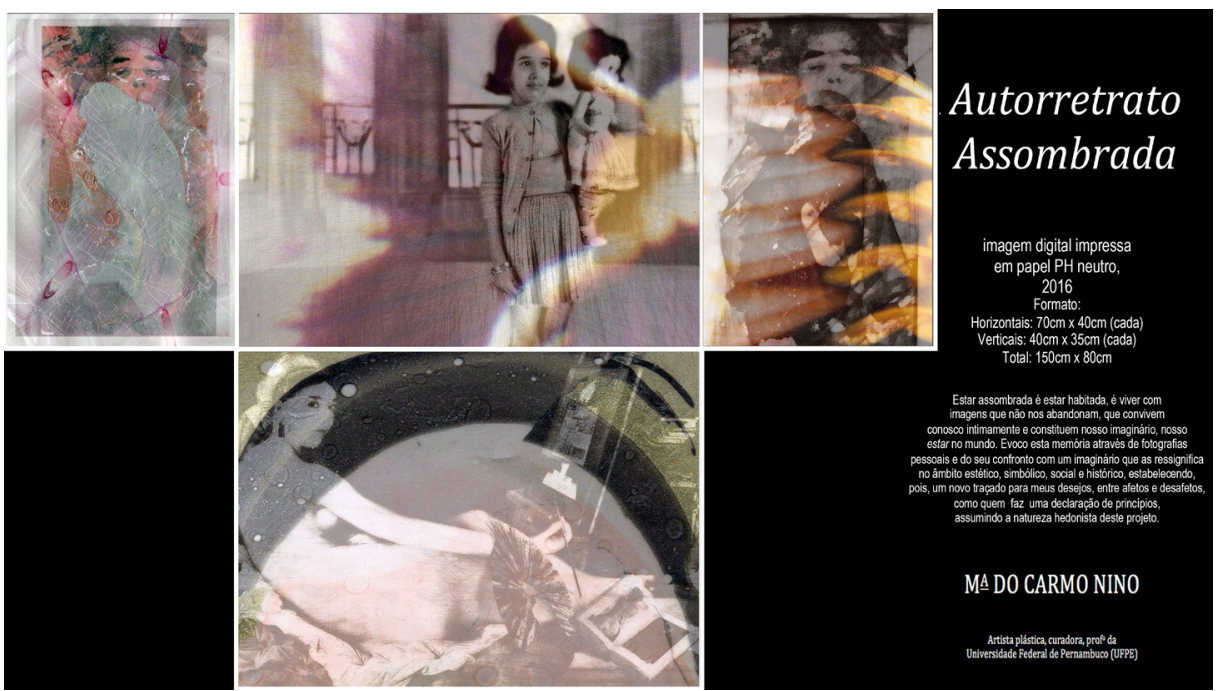

Figura 1: Autoretrato Assombrada, Maria do Carmo Nino

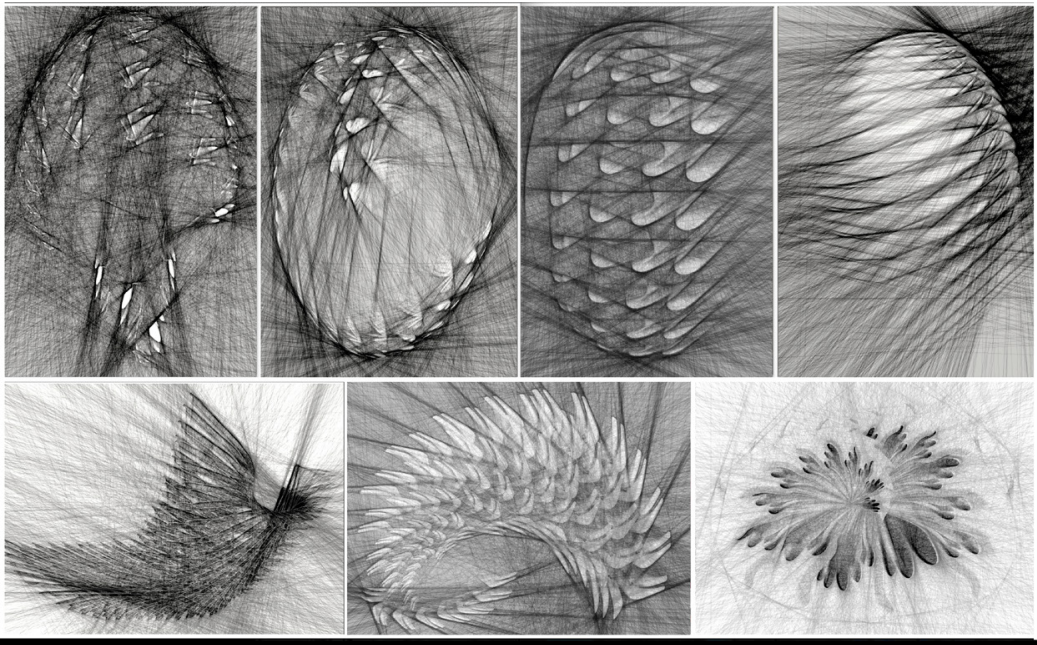

Lugares de Invenção I

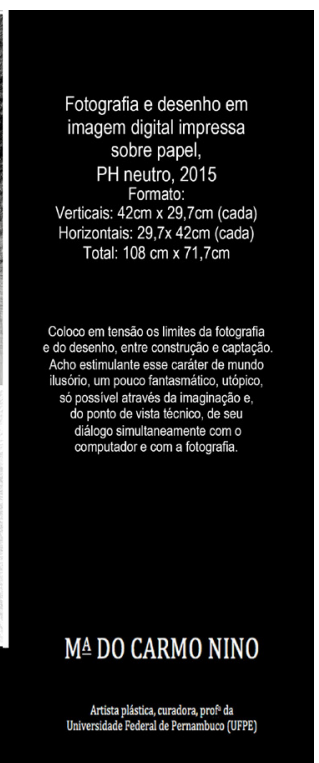

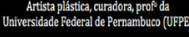

Figura 2: Lugares de Invenção I, Maria do Carmo Nino

\section{RELATOS DE DUAS EXPERIÊNCIAS}

Admiro uma grande quantidade de artistas, e a atividade docente me estimula à renovação de referências, mas se tivesse que destacar alguns, seriam aqueles que souberam conjugar sua própria prática com a teoria e em alguns casos a docência, e talvez por todas estas razões o caráter metalinguístico me atraia, pois propicia a explicitação autoconsciente como principio crítico e criador. 


\section{EXPERIÊNCIA PRIMEIRA ${ }^{1}$}

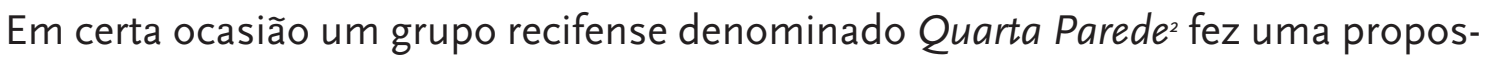
ta artística que consistiu em convite endereçado a todos que assim o desejassem, para participação da ação de ocupação coletiva do prédio vizinho ao Museu de Arte Moderna Aluízio Magalhães (MAMAM), programado durante o SPA - Semana de Artes Visuais de Recife, entre três e oito de novembro de 2003. O projeto teve o sugestivo nome de "Projeto MAMÃE" e se propôs a abrigar, sem restrições de ordem temática, discriminações ou vetos de nenhuma espécie3, as propostas de vários artistas (ou aspirantes), mais ou menos experientes segundo cada caso, com variações de grau no reconhecimento de seu trabalho por parte do sistema institucional das artes, em um intencional, claro e transgressor contraponto à situação estabelecida de liderança de um espaço importante para a cidade do Recife como o MAMAM, que abriga exposições de artistas que se destacam em um cenário nacional e internacional, onde os critérios de escolha são complexos e nem sempre ao alcance do conhecimento ou compreensão de todos e contra os quais a classe artística às vezes se insurge.

Nesta curadoria às avessas realizada pelo grupo, as obras não seriam escolhidas por suas qualidades artísticas (ou ausência delas) e o público teria a oportunidade de ver reunidas no mesmo espaço propostas estéticas que democraticamente o habitavam, com níveis de maturação e sofisticação muito diferentes entre si, e teria a possibilidade de julgar por ele mesmo as suas próprias predileções nesta "família" heteróclita além de, ao mesmo tempo, experimentar uma certa sensação de não-familiaridade, para não dizer de espanto, devido às condições materiais do local e de como as obras estavam expostas, sem necessariamente estabelecerem diálogos de significação - temática ou outra - entre si, como normalmente se espera que ocorra.

O imóvel se encontrava em processo de reforma no andar térreo, sendo que foi facultado a todos os eventuais integrantes, apenas o uso do andar superior. Os diversos tipos de ocupação por parte dos artistas participantes do projeto demonstraram posteriormente como cada um entendeu aquele lugar: para muitos significou claramente um espaço de liberdade, acolhedor, como se espera que uma mãe seja, lugar portador de uma história que lhe era própria, não somente concebido inicialmente para abrigar exposições de arte, mas em situação de quase abandono. As condições de precariedade física do ambiente, impregnado de texturas de toda a ordem, caótico como um espaço em ruínas, sem dúvida agiram também como um certo aspecto limitador até mesmo por medida de segurança, mas foram, no entanto, incorporadas em muitas das propostas presentes, tendo sido em alguns casos, inclusive, reforçadas com moderação. De uma maneira geral, a palavra "ruína" indexa uma situação de deterioração de um dado imóvel ou bem móvel, devido simplesmente ao desgaste natural do tempo ou outro, sem que tenha havido suficiente empenho para se deter as alterações em relação ao seu estado

\footnotetext{
'Este relato foi em parte extraído de um texto da minha autoria (Nino, 2011).

2 O grupo, na época era composto pelos artistas plásticos Daviana Barros, Izidório Cavalcanti e Mozart Santos, todos atuantes na cidade do Recife.

${ }^{3}$ Bastando apenas o desejo de mostrar o seu trabalho e o pagamento de uma taxa para complementar o aluguer do imóvel.
} 
original. Por outro lado, as ruínas são portadoras de um apelo estético inegável, principalmente quando apontam para recordações do passado, celebrações de utopias enraizadas não no futuro, mas exatamente na história pregressa, imaginária ou não, como tantas vezes a pintura, a literatura e o cinema souberam celebrar. Pode-se dizer sem muito receio de uma generalização excessiva, que os artistas em sua vasta maioria não se detiveram neste aspecto da história do local, eles se viram divididos, grosso modo, entre a situação de levar uma obra preexistente e adequá-la ao dito espaço, e aquela de pensar em algo que pudesse de modo mais íntimo e visceral existir a partir da confrontação do seu estado atual. Eis reproduções de algumas das intervenções no espaço:

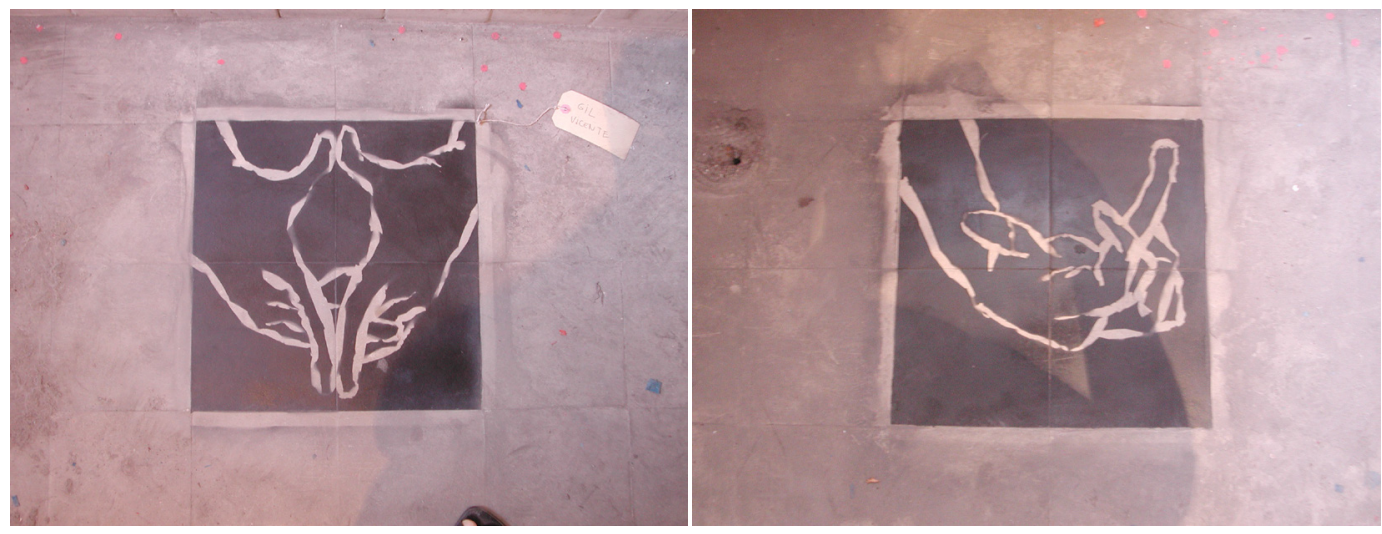

Figura 3: Gil Vicente, S/ Título, Spa 2003

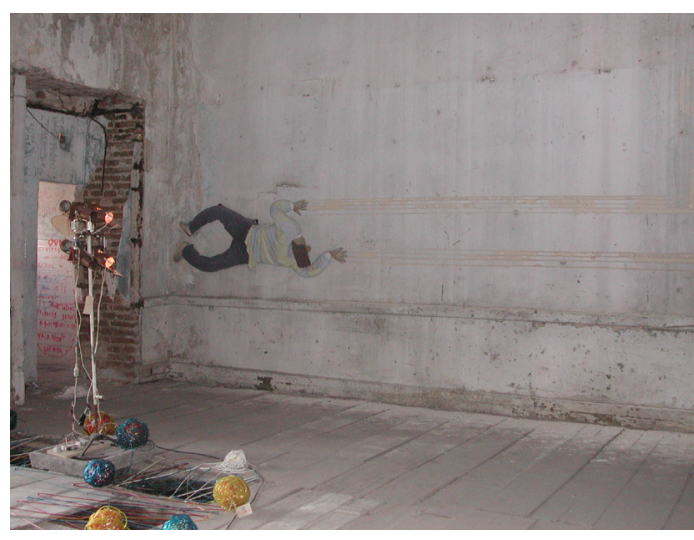

Figura 4: Braz Marinho, S/ Título, Spa 2003

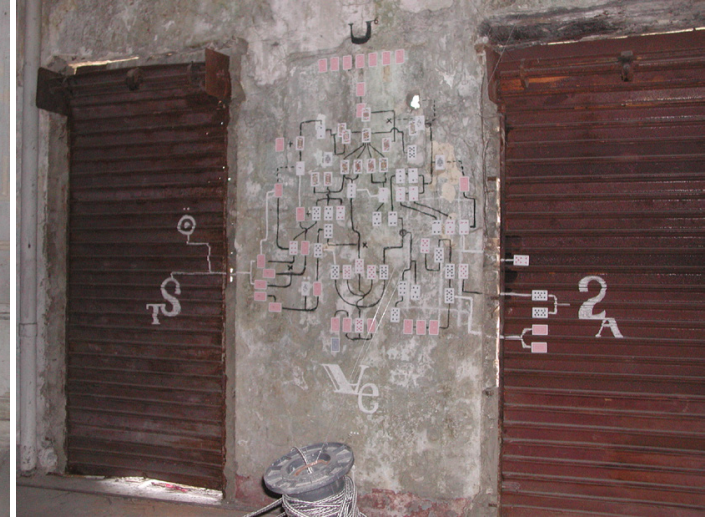

Figura 5: Felippe Lyra, S/ Título, Spa 2003 

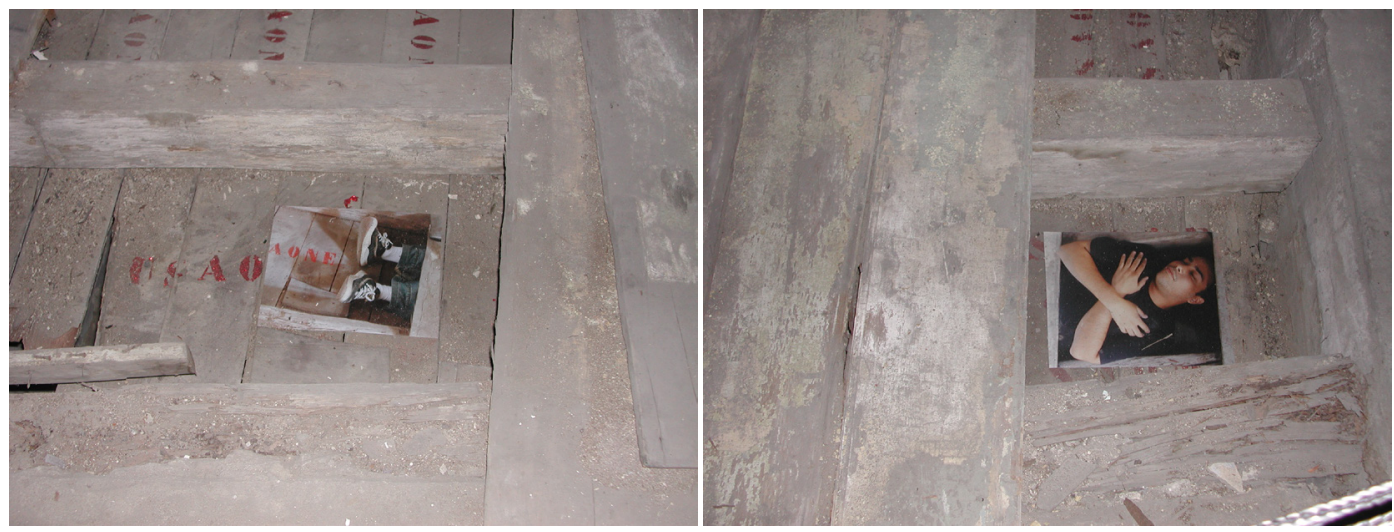

Figuras 6 e 7: Bruno Vilela, S/ Título, Spa 2003

Em meu caso específico, ao visitar o espaço e me dar conta do seu real estado físico, onde as condições das instalações em tudo o opunham ao seu vizinho, percebi o quão seria interessante corroborar na minha proposta o espírito que deu origem ao projeto, inaugurado pelo grupo, afinal de contas foi esta inicialmente para mim a principal motivação de inclusão no mesmo. Apesar de não ser uma premissa de participação pré-determinada, era por demais tentador fazer um uso deste espaço que levasse em conta a sua especificidade de localização (vizinho ao principal museu da cidade), e a possibilidade de desenvolver um comentário estético que fosse nesta direção me veio à mente.

Observando mais atentamente in loco a planta do imóvel, percebi um nicho na parede, com os tijolos aparentes, em forma de porta e ao questionar onde daria, fui então informada que se tratava de uma antiga comunicação entre os edifícios, ambos então da propriedade da Prefeitura de Recife. A passagem que dá acesso ao que é hoje a circulação do museu, deve ter sido fechada na ocasião da venda do imóvel a um proprietário particular.

O fato é que ao perceber a pré-existência da comunicação, surgiu em mim a vontade imediata de restaurá-la em uma proposta estética, que no entanto se faria dentro dos moldes de um comentário crítico, embora impregnado de certo humor e ironia. Decisão tomada eu parti, então, para as negociações com os administradores do espaço do museu sem o qual obviamente não teria conseguido meu intento.

A obra Olho Mágico toma emprestado seu nome dos dispositivos para fins de segurança que se encontram nas portas das entradas principais de casas ou de apartamentos residenciais e que nos permite, a partir do interior do espaço dividido pela mesma, que vejamos sem sermos vistos. Na realidade, ela lhes empresta não apenas o nome, mas a aparência que se enquadra com uma apresentação reverberando os significados acionados pelos seus usos em nosso contexto social cotidiano, pelo menos ao primeiro ou incauto olhar: trata-se realmente de uma porta de dois metros e dez centímetros por um metro de largura em madeira natural, não pintada, incrustada em um nicho na parede, onde se verifica facilmente o citado elemento colocado a uma altura apenas um pouco acima do encontro entre as duas linhas diagonais formadas a partir dos cantos superiores da porta, exatamente sobre a linha de demarcação resultante da junção das 
duas metades de madeira que a formam, o que significa cerca de $120 \mathrm{~cm}$ do limite inferior; altura não muito usual, é verdade, já que o observador médio adulto deve prioritariamente curvar-se para tentar perceber o que ou mesmo se algo ou alguém se descortina no outro lado, como todo o conjunto deixa naturalmente presumir.

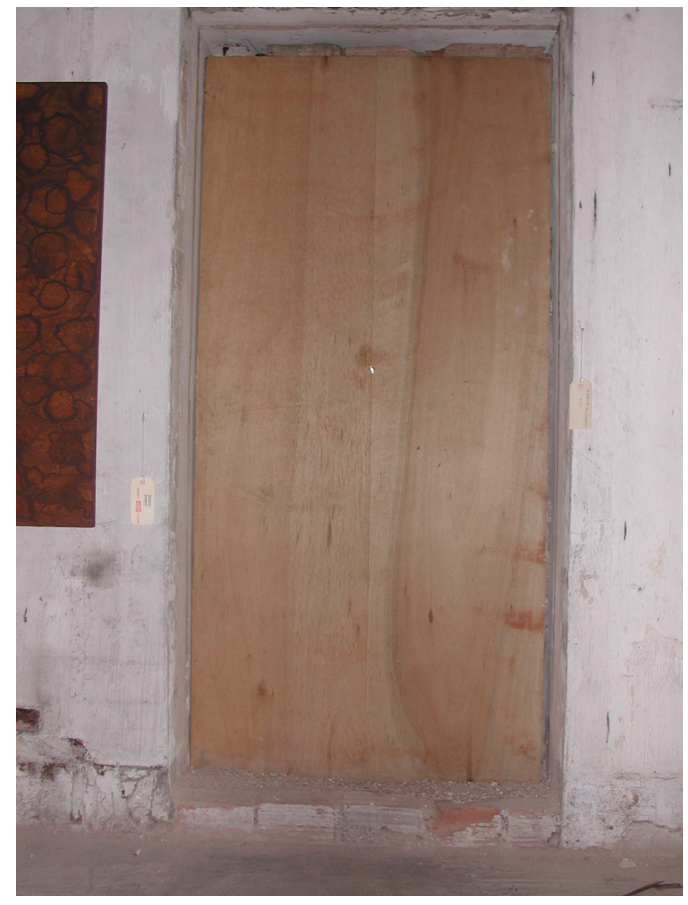

Figura 8: Maria do Carmo Nino, Olho Mágico, Spa 2003

O estranhamento vislumbra-se progressivamente ao nos darmos conta de que a função da porta como elemento de passagem entre dois espaços lhe é negada, uma vez que não é possível abri-la pois não existem fechaduras, maçanetas ou trincos; verifica-se também a base de tijolos no solo e, à devida distância, observa-se que ela apoia-se na realidade sobre uma parede maciça: literalmente um muro hermético e intransponível.

Acha-se assim confirmada para o público a intenção apriorística e irônica de apontar para uma impossibilidade de acesso efetivo ao espaço contíguo. A porta, neste contexto, nos faz lembrar o que poderia (mas não consegue) ser: abertura sobre um mistério, possuidora de um valor dinâmico de cunho inclusive psicológico, já que não somente ela indica a passagem entre dois limites bem definidos espacialmente, mas convida a ultrapassá-los.

Privados que somos da escolha entre a alternativa rítmica do fechar e do abrir, a esperança da iminência do acesso à revelação do espaço exterior aquele onde nos encontramos se concentra no pequeno orifício de vidro, que como se sabe, permite por sua vez um ângulo de visão ampliado e distanciado (como em uma objetiva grande angular). $\mathrm{O}$ acesso para nós agora se reduz à possibilidade de observar através do instrumento, que funciona então como contiguidade e extensão do olho humano.

Olhos mágicos ratificam a função das portas como obstáculos, estabelecendo uma linha divisória entre os espaços que através dela se comunicam e, neste caso, 
impossibilitada de ser aberta, a porta adere como uma pele ao muro que a sustenta, duplicando-o tanto em sua forma quanto em sua função. A existência aqui do orifício nos coloca na posição do voyeurs, de invasores de um espaço que em princípio nos é negado.

Impossível então não notar a inversão que se opera com a função geralmente atribuída ao uso socialmente banalizado do olho mágico: colocadas nas nossas residências, eles evitam na realidade que sejamos invadidos, pois permitem nosso controle sobre o outro, sobre aquele que segundo nossa decisão entrará ou não em nosso espaço; no entanto a situação que se verifica neste contexto nos coloca sob a perspectiva de agirmos desta feita como invasores, pois nos é possibilitado o fato de perscrutarmos à sua revelia, sem sermos por ele observados ou mesmo convidados a fazê-lo. Embora a ideia de "outro" (espaço ou indivíduo) seja um ponto nodal do trabalho, em princípio não temos como saber sobre sua consciência sobre o mesmo ou ainda se há pertinência em a considerarmos neste caso.

A efetivação do papel de invasor só se complementa através do olhar daquele que aceita o convite implícito pelo sistema montado ao visitar a exposição. $\mathrm{Na}$ realidade, o caráter artístico da obra só se revela de maneira intermitente, ou seja: desde que haja um observador que se dê o trabalho de curvar-se para olhar através da porta, ou, como sabemos, resumiria Duchamp: é aquele que olha que faz o quadro. Tal conjuntura está aqui potencializada em uma situação quase limite, sempre a ponto de não ocorrer. Isto acontece porque a arte tem tanto a ver com ações quanto com objetos, como diria também Goodman (1999) e se a obra necessita de ser posta em marcha é que sua imediaticidade não é jamais integral. Como médium (lugar, meio) que é da reflexão, ela traz inevitavelmente implícita a noção de variações anacrônicas, ou seja, da necessidade de tempos distintos para que o processo de sua compreensão se efetive plenamente.

Em Olho Mágico, a transformação de uma parede cega em uma espécie de janela, na medida em que se oferece ao olhar, intermediando os possíveis diálogos entre o que agora se percebe como espaço interior e exterior, está longe de ser neutra. Na realidade historicamente a inserção da ideia de janela determina uma nova maneira de se relacionar com o espaço. Instaura uma relação de vigília, mas também de permanentes mantedores deste estado. O desejo que aqui se estabelece, ou simplesmente a musa e neste caso incorporado pelo próprio espaço do MAMAM, que é contíguo, mas acessível apenas unilateralmente através do olhar, atesta o seu estado permanente de frustração inexorável. Apenas o olhar é mágico e ultrapassa as fronteiras.

Tudo se passou, então, como se meu próprio ponto de vista crítico sobre o Projeto Mamãe se materializasse visualmente nesta peça: como obra específica só fazendo sentido no lugar exato que constituiu aquele de sua apresentação ao público, ela efetivou-se espacialmente incrustada na proposta expositiva do Quarta Parede, como um comentário autorreferencial, paródico, uma interface à proposta do grupo, que tendo-a sintetizado, enfatizou-a, de modo redobrado, para o espectador, como em uma espécie de mise em abîme, sem deixar no entanto de apontar para o fato de que o objeto de desejo permanece inalcançável. 


\section{EXPERIÊNCIA SEGUNDA ${ }^{4}$}

A segunda experiência a ser relatada diz respeito à curadoria da exposição ContidoNãoContido ocorrida no Museu Aloísio Magalhães - MAMAM, no período entre março e setembro de 2010. Esta empreitada curatorial adveio de um convite por parte da direção do museu para ser feita em parceria com a curadora Clarissa Diniz para que organizássemos a exposição que marcaria a reabertura do espaço após um período de fechamento que se estendeu por dois anos, devido a reformas no seu prédio. As incontornáveis premissas iniciais com as quais lidaríamos, seria a de que a mostra se restringiria necessariamente às obras que fazem parte do acervo do museu e que os trabalhos escolhidos deveriam ficar expostos por uma duração mais prolongada, de aproximadamente seis meses.

Estas demandas restritivas nos colocaram de imediato diante do impasse desafiador de trabalhar a partir de um acervo que sabíamos de antemão ser bastante incompleto no que tange o fato de reconhecidamente insatisfatório como representativo da arte produzida a partir do século XX em Pernambuco, no amplo período compreendido desde 1900 até aquela data. A coleção compõe-se de obras de cerca de 250 artistas de diferentes origens, do Estado ou não, variadas pesquisas e trajetórias de importância em níveis distintos, com peças executadas em numerosas técnicas e linguagens, porém em quantidade flagrantemente insuficiente para uma completa historiografia sobre a arte feita em Pernambuco do período em questão.

A análise destes fatos nos conduziu à decisão de seguir um modelo curatorial de cunho adaptável e experimental, uma exposição - processo extensivo a um ciclo de três etapas/recortes distintos que foram inaugurados a cada dois meses. Outra decisão de importância crucial foi a de que propusemos ampliar a parceria da responsabilidade da curadoria com a inclusão da equipe do EducAtivo Mamam. Ficou decidido, a partir da longa gestação de todo o processo, que cada uma das duas primeiras abordariam as várias décadas envolvidas na arte praticada em Pernambuco, porém trariam escolhas de artistas, obras e eixos de abordagem diferenciados a cada vez. O terceiro recorte, talvez o mais polêmico, representaria um encerramento provocativo do ciclo, ao propor a ocupação do espaço expositivo baseando-se no confronto dos dois artistas com o maior número de obras presentes no acervo Mamam, mas com níveis bem diferenciados de legitimação no cenário local, regional e nacional das artes plásticas.

É forçoso reconhecer que abarcar um espectro amplo de problematizações estruturais acerca de cruciais papéis institucionais que regem o sistema de artes a partir de seu próprio exemplo, exigiu um certo desprendimento por parte da direção do museu e enfatizo a acolhida positiva que a proposta teve na figura de sua diretora e do EducAtivo, desde o seu início. A direção tomada, como consequência prevista, deu visibilidade às fragilidades do próprio acervo, sistematizou um modo de operação do trabalho em equipe envolvendo o EducAtivo em novos formatos de atuação e responsabilidades, intensificou sobremaneira o período de pré-produção para a equipe com a pesquisa e a confecção das inúmeras pastas, além de que desafiou o público com novos modos de apresentação e a demanda de níveis de disponibilidades de recepção específicas.

${ }_{4}^{4}$ Este relato foi em parte extraído de um texto da minha autoria (Nino, 2015). 
Todo o ocorrido revestiu-se de uma dimensão metalinguística, de uma autorreferencialidade que faz com que a experiência se retorne para si própria, porém, sem que no entanto o conhecimento adquirido deixe de ser útil para além de seu caso específico, podendo servir de reflexão aplicável a outros exemplos nacionais ou locais. ContidoNãoContido incorporou, de fato, uma atitude onde a oportunidade de se perguntar sobre as vulnerabilidades das nossas políticas públicas e apontar as dificuldades da constituição e preservação do nosso patrimônio cultural, além de detectar as consequências da ausência de política de aquisição de obras no início da constituição do acervo, uma vez que ela foi implantada tardiamente, pareciam importantes demais para serem deixadas de lado. Sua pregnância se situa dentro de uma perspectiva onde esta série de experiências se conectariam, apontando para um devir, transformando o espaço institucional representado pelo museu em um laboratório. Faz uma apologia da necessidade da crise, ao demandar um apelo à reflexão sobre os seus respectivos papéis sociais como agente legitimador, e também evidentemente aquele do curador como detentor de um discurso oficial e determinante. $\mathrm{O}$ que se questiona é o indiscutível papel social da arte em relação a aspectos da vida.

O setor do educativo, neste caso, ao invés de lidar com a reprodução - ainda que reconhecidamente com potencialidade criativa - de um discurso a partir de uma escolha concluída e de constituição alheia a ele, foi incluído nas etapas da seleção dos autores, das obras, e de sua montagem. Isto sem dúvidas trouxe o benefício de um maior conhecimento interpretativo das obras por parte dos membros do EducAtivo, o que favoreceu o próprio processo de mediação, além de implicá-los mais diretamente no trato com os visitantes que chegavam ao espaço com expectativas de implemento de legitimação institucional, o que confirma o que o pertencimento a uma coleção pública parece, ainda hoje, encarnar junto aos próprios artistas, educadores e às pessoas em geral.

Esta percepção dialógica entre as tarefas desempenhadas amplia o papel do educativo inserindo-o diretamente em várias atividades dentro da instituição museal, ao invés de, como observa-se na maioria dos casos, ser percebido como um setor à parte. O reconhecimento da importância do setor educativo sofreu modificações positivas ao longo de sua história no sistema das artes e hoje nos parece inquestionável, embora reconheçamos que este, infelizmente, não seja um posicionamento que possamos afirmar ser unânime no Brasil. Podemos enfim afirmar tratar-se de um apelo para que os estereótipos e os preconceitos possam ser, senão dissipados, pelo menos amenizados, recontextualizados ou simplesmente repensados criticamente, dando espaço para o cumprimento de um dos papéis importantes ligados a uma curadoria e a uma instituição como o museu em geral, que é o de ser um dos agentes em um processo de educação não formal.

A forma de comunicação visual pensada para a divulgação na época é representada pelo modelo da fita de Mœbius, seguido do título redigido sem espaços, estabelecendo um potencial horizonte de continuidade entre os termos que, em primeira instância, são vistos como opostos e resumem muito bem este estado de coisas. Afinal a ambiguidade da característica espacialidade moebiana erigida como logomarca, se mostrou 
ideal para dar o tom: ela engendra a ilusão de uma linha fronteiriça entre dois espaços, quando na realidade temos apenas um. O que aparenta ser descontínuo revela-se como continuidade, instaura a temporalidade na espacialidade, como em um gerúndio, um presente contínuo.

Dentro, fora, exclusão, inclusão, contido, não contido... o que significa em termos de inserção ter sua obra em um acervo e a mesma nunca ter sido mostrada em público? O que faz que a obra de um artista seja recebida positivamente por um determinado grupo de profissionais do establishment e outro não? Marcel Duchamp já alertava para o fato de que dentro dos museus não estão necessariamente preservados o que de melhor se produziu em arte, embora esta seja exatamente a crença mais partilhada no senso comum. Consequentemente, este símbolo topológico fascinante e paradoxal traduziu claramente o nosso conceito-guia, ao dar visibilidade à questões fundamentais que atingem toda a proposta: onde pairam os convenientes limites que nos asseguram com a sua falsa impressão de estabilidade? Em que medida configurar-lhes uma clara existência ainda é operatório na maneira como funcionamos socialmente hoje? Ou mais, ainda, como um determinado sistema pode se autocompreender?

Em ContidoNãoContido, em cada um dos três momentos que marcaram junto ao público a apresentação dos recortes distintos, ao adentrar na cena expositiva, o visitante percebia que se encontrava diante de um modelo que não correspondia à dinâmica que normalmente se verifica em mostras expositivas de artes visuais. Isto provavelmente Ihes provocou um sentimento de deslocamento, pois, além das obras expostas, havia um mobiliário específico, pouco usual em exposições, determinando dois grupos compostos de pastas de arquivos, dossiês individuais com informações conseguidas após intensas pesquisas realizadas pela equipe no período de pré-produção, sobre os artistas da década correspondente, onde se lia "contidos" e "não contidos", referindo-se ao fato de terem ou não obras que os representassem no acervo, naquele momento específico.

O primeiro recorte contou com um conjunto de obras organizadas em cinco grandes períodos (1900-1930, 1940-1950, 1960-1970, 1980-1990, 2000-2010) e que ocuparam ambientes diversos do museu, indo da recepção às paredes, passando pelo teto e pelo chão, em modos de apresentação condizentes com a liberdade que acompanhou as experiências artísticas ao longo do século. A premissa cronológica foi a opção escolhida para deixar mais claramente perceptível as desigualdades do acervo, por exemplo, a escassez de obras referentes às décadas de 1940 e 1950 em confronto com aquelas mais numerosas do final do século. O segundo recorte organizou as obras de modo a trazer à tona o embate travado entre os paradigmas acadêmicos, modernistas e regionalistas que percorreram a história da arte de Pernambuco. No terceiro recorte houve o confronto entre os dois artistas: foi um estudo de caso da aquisição das coleções "Luiz Carlos Guilherme" e "João Câmara", que, ao lado de Samico e Vicente do Rego Monteiro, são os maiores representantes do acervo do museu. Contou também com um vídeo sobre depoimentos de quem participou da aquisição das obras, seguido de documentos da época no espaço expositivo. Esta exposição, polêmica, obriga o público a (re)considerar as suas posturas individuais frente a modelos institucionais pré-estabelecidos referentes à legitimação dos vários setores compreendidos pelo sistema das artes. 

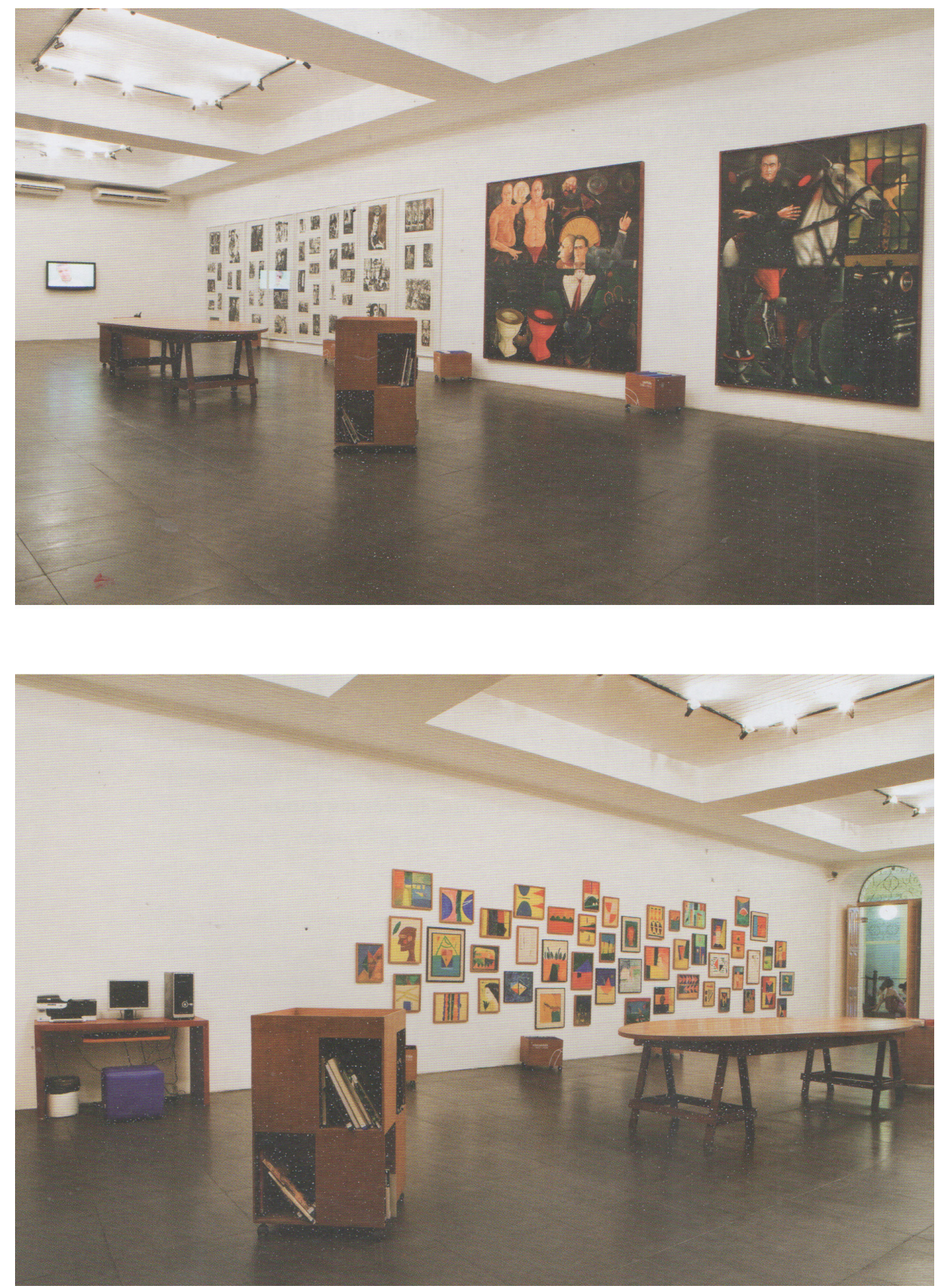

Figuras 9 e 10: Exposição ContidoNãoContido

Uma longa mesa com puffs e cadeiras no centro do espaço dispunha de vários catálogos e livros em estantes da biblioteca do museu para serem consultados, havia também uma impressora multifuncional, papéis e um computador conectado à internet que poderia ser acessado pelo visitante, caso ele se sentisse estimulado a fazer pesquisas sobre um determinado artista, presente ou não na coleção, sobre o período do seu interesse específico ou mesmo sobre outros aspectos ligados à arte. Isto colocava certos 
desafios imediatos junto ao público em seus hábitos, pois o tempo de visitação, como numa sala de leitura, se veria inegavelmente dilatado pela demanda de interação com as diversas pastas, além de que o conteúdo das mesmas não apenas poderia ser consultado, mas ampliado a gosto com informações, catálogos, artigos de jornal, imagens de obras mais atualizadas, enfim, qualquer dado sobre um determinado artista consultado, afim de complementar as pastas já existentes ou criar novos arquivos, sendo que para isso à guisa de estímulo, foram colocadas estrategicamente pastas vazias, como um indicador de que se esperava que elas fossem preenchidas para a constituição de novos dossiês.

Este convite ao estudo, acolhedor e lúdico ao mesmo tempo, propôs a sociabilização da informação em grupos, ao relacionamento interpretativo de poéticas, dando a perceber o elo com a nossa história através de artistas variados. Segundo o depoimento dos mediadores, porém, a reação dos visitantes era tímida, não interagiam com a intensidade almejada e nem nos diversos níveis como esperava a equipe. Pode-se estimar que a falta de iniciativas deste tipo de demanda no âmbito das exposições, ao criar um certo estranhamento, tenha contribuído para que o resultado ficasse aquém do ansiado e mesmo a pouca inclusão de novas pastas verificada ao longo dos seis meses do ciclo de exposições, indica sem dúvida que alguns novos hábitos não recebem naturalmente uma adesão imediata, podendo no entanto, esperemos, serem assimilados gradualmente. Anseio isto porque acho que a insistência em pensar este modelo onde o processo contínuo de ampliação com o estímulo à complementação por parte do visitante, tem um importante papel a cumprir na formação e ampliação de público interessado em artes plásticas e também na ênfase à consciência sobre a importância da arte, para a compreensão da nossa história e em certos modos de funcionamento da sociedade.

A potencial alimentação de um acervo de novas informações além de colaborar no adensamento dos registros e documentos acerca da história da arte local, poderia eventualmente auxiliar nas próximas aquisições a serem feitas para a instituição. A explicitação deste fato no texto de apresentação na parede, junto ao fato sem precedentes do estímulo para que a população pernambucana falasse de sua própria arte diretamente à instituição, sem mencionar o tema da exposição que apontava diretamente para a ideia de passagem fluída ente dois pólos indicadores de (ex)inclusão, por certo fomentou uma expectativa junto ao artistas que por razões de natureza diversa não se veem devidamente ou mesmo de modo algum, representados na coleção.

A ideia de reconhecimento institucional, sobretudo em artistas mais jovens, exerce um fascínio inegável e nos faz lembrar como funciona ainda hoje - em tempos da existência de espaços bem mais democráticos como internet, blogs e YouTube - a motivação no mercado de trocas por onde circula o artista para construir sua trajetória. Seja a coleção de ordem privada ou institucional, os salões oficiais, ou mesmo apenas a sua satisfação pessoal, o fato é que indiferentemente do nicho aonde o artista escolhe se inserir e se acomodar às consequências, trata-se de um mercado que não deixa nunca de carregar consigo características de peso econômico, político e simbólico, que refletem diretamente na sua legitimação como artista junto aos pares, à família e amigos ou à sociedade em geral, embora seja em escalas de valoração distintas. 
O desejo de exercer até onde for possível, um certo controle sobre a própria vida, de autogovernar-se, o que compreende a nossa capacidade de basearmos a nossa imagem social e pessoal tendo como horizonte as próprias escolhas de valores, não deixando-se seduzir por uma moral reguladora de cunho dominante, subentende um constante exercício de revisão, para dar lugar inclusive à necessária renovação. No que foi possível para a equipe responsável, procuramos com ContidoNãoContido enfatizar para o visitante da exposição a necessidade de desconstruir crítica e positivamente a "reverência de tom forçado" com a qual o museu é frequentemente visto.

\section{REFERÊNCIAS BIBLIOGRÁFICAS}

Goodman, N. (1999). Artifices d'exposition. Cahiers du MNAM, 41, 13.

Nino, M. C. (2011). Pontuações de um Percurso. In S. Pedrosa (Ed.), O Artista Contemporâneo e o Ensino da Arte (pp. 214-223). Recife: MXM Gráfica Ed. Ltda. \& Ed. Universitária da UFPE.

Nino, M. C. (2015). Continuidades e Alternâncias, onde estão os limites? In C. Diniz de Moura (Ed.), Contidonaocontido. Recife: ed. Ideário.

\section{NOTA BIOGRÁFICA}

Maria do Carmo Nino possui doutoramento em Arts Plastiques et Sciences de I Art pela Universidade de Paris (Panthéon-Sorbonne). Atualmente é professora adjunta da Universidade Federal de Pernambuco. Tem experiência na área da arte contemporânea, fotografia, história da arte e crítica de arte, cinema e literatura.

E-mail: carmonino@gmail.com

Endereço: Universidade Federal de Pernambuco, Centro de Artes e Comunicação, Departamento de Teoria da Arte e Expressão Artística. Av Prof.Moraes Rego, 1235 Cidade Universitária, 50670901 - Recife, PE - Brasil

\section{* Submetido: 11/05/2017 \\ * Aceite: 12/06/2017}

